\title{
EVALUATION OF CHROMITES DERIVED FROM KIMBERLITES AND IMPLICATIONS FOR DIAMOND EXPLORATION PROGRAMS
}

\author{
Andrew Menzies ${ }^{1}$, Madelaine Frazenburg ${ }^{1}$, Mike Baumgartner ${ }^{1}$, John Gurney ${ }^{1}$, Rory Moore ${ }^{2}$ \\ ${ }^{1}$ Mineral Services, South Africa; ${ }^{2}$ Mineral Services, Canada
}

\section{INTRODUCTION}

Chromites are one of the major indicator minerals recovered during exploration sampling programs for primary diamond deposits. In certain areas, such as parts of Australia, it is the dominant kimberlitic indicator mineral to survive the frequently prevailing laterisation process occurring in surface soils. In addition to tracing mantle derived "xenocryst" chromites back to their potential kimberlite or lamproite source, the mineral compositions of these grains may be used to assist in the evaluation of the diamond potential of this source.

This presentation documents the primary magmatic alteration and resultant elemental zonation of chromites found in kimberlites and lamproites. The work is based on the investigation of chromites from a variety of kimberlites from around the world, including South Africa, Australia, and Canada. Any compositional changes in a chromite are effectively demonstrated using backscatter (BSE) imaging capabilities and the elemental mapping functionality LEO 1450 scanning electron microscope (SEM) with ED/WD Oxford detectors at Mineral Services Laboratories in Cape Town, South Africa. All grains were extracted from the concentrate of crushed kimberlite, mounted in epoxy resin and polished.

\section{OBSERVED CHROMITE ALTERATION}

Chromite compositions can vary dramatically depending on the physiochemical conditions within the source mantle, and subsequent alteration brought about by mantle metasomatism and/or interaction with the kimberlitic- or proto-kimberlitic type melt that transports these grains to the Earth's surface.

This study has revealed that any given chromite may display two (commonly) concentric zones of compositional and/or textural alteration as well as two different types of metasomatic infiltration, each with a distinct geochemical signature. The two concentric rims or rinds can be of variable thickness and may even ultimately overprint the entire grain. In addition, this concentric alteration may change the physical texture/properties of the grain and may, after polishing, be observed by binocular microscope under reflected light or SEM Secondary electron (SE)/Backscatter electron (BSE) imaging. BSE images of three chromite grains, each displaying various extents of the concentric alteration are given in Figure 1. These range from a noticeable rim in the top image, to almost complete overprinting in the bottom image.

The concentric alteration need not work pervasively from the outer rim of the chromite towards the core. BSE images of three chromite grains with unusual alteration patterns are shown in Figure 2. In addition, it should be realized that not all grains recovered will be euhedral but in all likelihood will be broken fragments. Thus the proportion of the grain that is altered and its zonation pattern my not be inherently obvious. For example, the core of the chromite may be overprinted or, if the grain is broken, only comprise a minor portion of the grain.

Elemental changes between the original composition and the alteration rims can be varied in nature and severity. It is apparent from the various BSE images displayed in Figures 1 and 2 that the geochemical compositions of the various zones are different - the brighter the shading, the higher the backscatter intensity and thus the greater the average $\mathrm{Z}$ (atomic number) of that area of the mineral grain. Two examples of the range in geochemical changes are shown using elemental mapping (Figure 3 ) and point analyses (Table 1). These two examples do not represent the entire variety of the changes observed to date, but are used to highlight the possible extreme magnitude in geochemical composition of the various zones within a chromite.

Elemental maps of $\mathrm{Al}, \mathrm{Fe}$, and $\mathrm{Si}$ in a chromite grain are displayed in Figure 3. It is apparent that $\mathrm{Al}$ and $\mathrm{Fe}$ have decreased substantially between the core and surrounding thick zone of alteration, whilst $\mathrm{Mg}$ and $\mathrm{Ti}$ (and $\mathrm{Cr}$ to a lesser extent) have increased. In addition, there is modal metasomatic infiltration of both $\mathrm{Si}$ and $\mathrm{Mg}$, and possibly $\mathrm{Zn}$, into the alteration zone. 


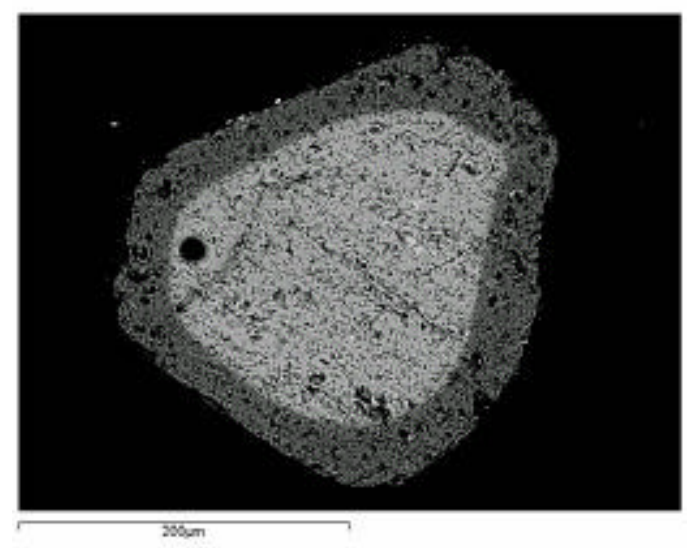

The compositional differences observed in a solitary chromite grain are further illustrated in Figure 4. The top-most BSE image is of the entire grain, and displays a noticeable rim. In the bottom magnified SE image, however, the slightly darker rim is not the rim observed in the BSE image, but a second rim with a distinctly different composition. The rim observed in the BSE image is not distinguished in the SE image and does not display any distinctive surfical features. The extremely varied compositions in these two rims (inner and outer) relative to the original (core) of the chromite is shown in the major element data given in Table 1.

The compositional changes observed in the chromite populations are inconsistent and vary between localities. For example, at one locality the most commonly observed elemental changes results in an increase in $\mathrm{Ti}, \mathrm{Mg}$ and (to a lesser degree) $\mathrm{Cr}$, and a decrease in $\mathrm{Fe}$ and $\mathrm{Al}$, whereas at a different locality the alteration is presented as an increase in $\mathrm{Al}$ and $\mathrm{Mg}$ and a decrease in $\mathrm{Fe}$.

\section{DISCUSSION}

It is apparent that kimberlite-derived chromites experience, and geochemically record, a multitude of events relating to mantle metasomatism (both modal and cryptic) and/or interaction with their host magma. Chromites have an important role in diamond exploration, from grassroots reconnaissance in a new area through to the evaluation of the diamond potential of a discovery. It is essential to classify the genetic origin of chromites correctly so that their significance can be correctly assessed.

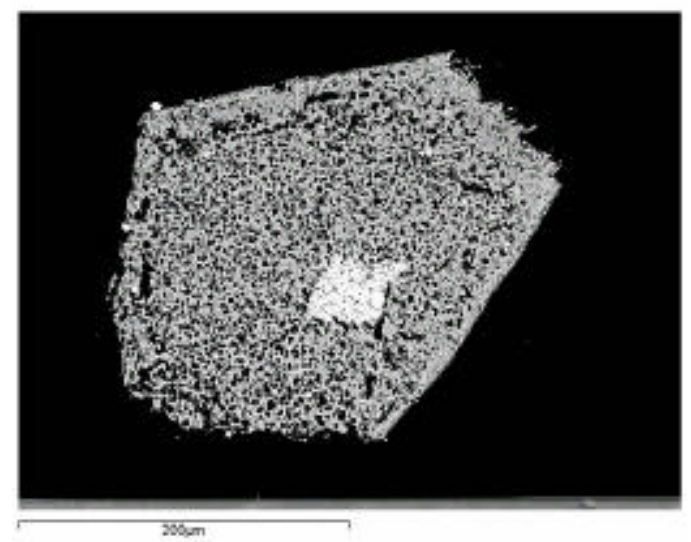

Chromites derived from non-kimberlitic crustal sources such as serpentinites, bonninites and chromitites can have compositions that overlap with mantle derived xenocryst chromites. However, the magmatic alteration seen on kimberlite or lamproite derived xenocryst chromites appears to be unique to these rocks and therefore their identification in chromites recovered during exploration programs may be highly significant in itself. Indicator minerals recovered in diamond exploration programs are often abraded or broken, causing the spatial definition of the original grain morphological rim and core to be lost. Consequently, without careful imaging and/or elemental mapping of individual chromites, it may not be possible to distinguish whether the original core or alteration rim of the grain has been analysed. Thus, the chromite may be incorrectly classified and any decision based on the resultant data may be misleading. 

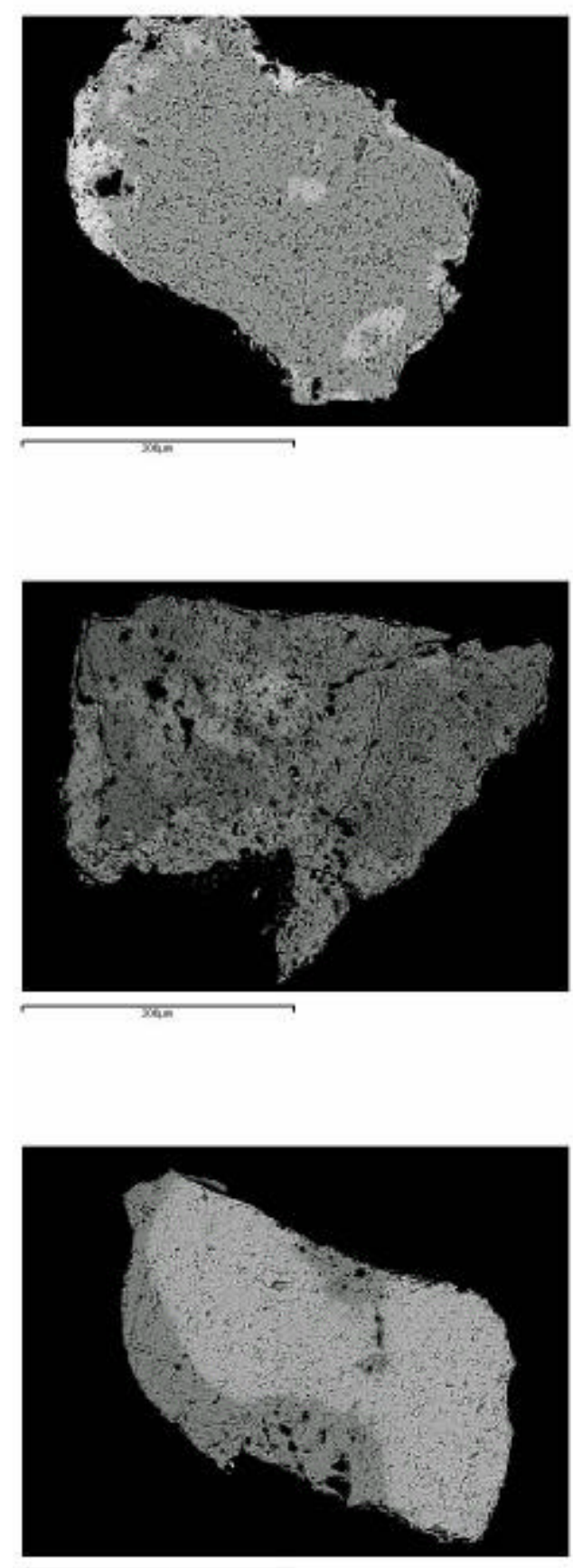

Figure 2: Backscatter electron images of three chromite grains that clearly highlight the variety of how the different zones can manifest themselves. The brighter the shading, the greater the backscatter intensity and thus the greater the average $\mathrm{Z}$ (atomic number) of the mineral, clearly indicating a significant change in geochemical composition.
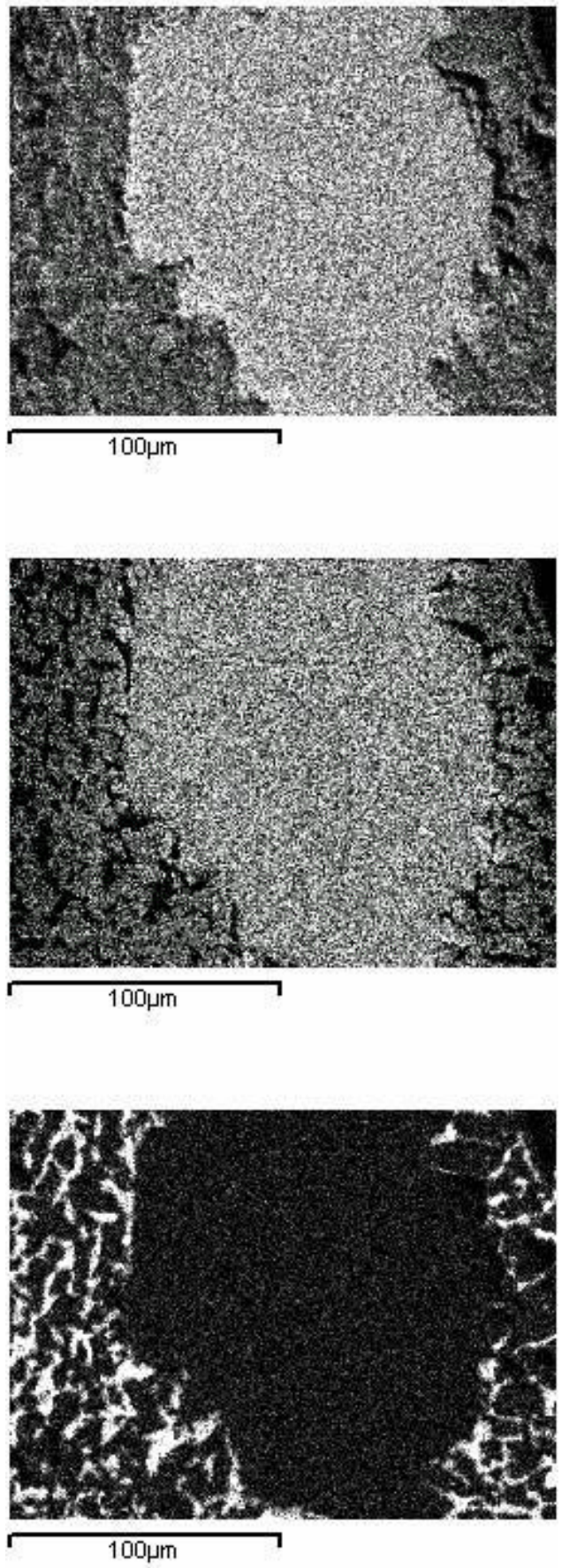

Figure 3: Various elemental scans of an altered chromite grain - from top to bottom: $\mathrm{Al}, \mathrm{Fe}$, and $\mathrm{Si}$. There is a distinct change in elemental concentrations between the original core composition and the surrounding altered zone. Note the pervasive infiltration of $\mathrm{Si}$ into the altered outer area of the grain. The brighter the shading, the greater the $x$-ray intensity, and thus the greater the concentration. 
Table 1: Example of geochemical variation observed in a chromite

\begin{tabular}{lrrr}
\hline & Core & Inner Rim & Outer Rim \\
\hline $\mathrm{SiO}_{2}$ & 0.00 & 0.17 & 0.15 \\
$\mathrm{TiO}_{2}$ & 3.19 & 3.37 & 2.39 \\
$\mathrm{Al}_{2} \mathrm{O}_{3}$ & 1.68 & 5.55 & 50.61 \\
$\mathrm{Cr}_{2} \mathrm{O}_{3}$ & 55.35 & 56.38 & 4.10 \\
$\mathrm{FeOt}$ & 29.14 & 21.05 & 19.57 \\
$\mathrm{MnO}$ & 0.55 & 0.53 & 0.28 \\
$\mathrm{MgO}$ & 9.68 & 12.46 & 23.56 \\
$\mathrm{CaO}$ & 0.08 & 0.00 & 0.00 \\
$\mathrm{~V}_{2} \mathrm{O}_{5}$ & 0.52 & 0.52 & 0.00 \\
$\mathrm{ZnO}$ & 0.18 & 0.20 & 0.00 \\
$\mathrm{Total}$ & 100.37 & 100.23 & 100.66 \\
\hline
\end{tabular}
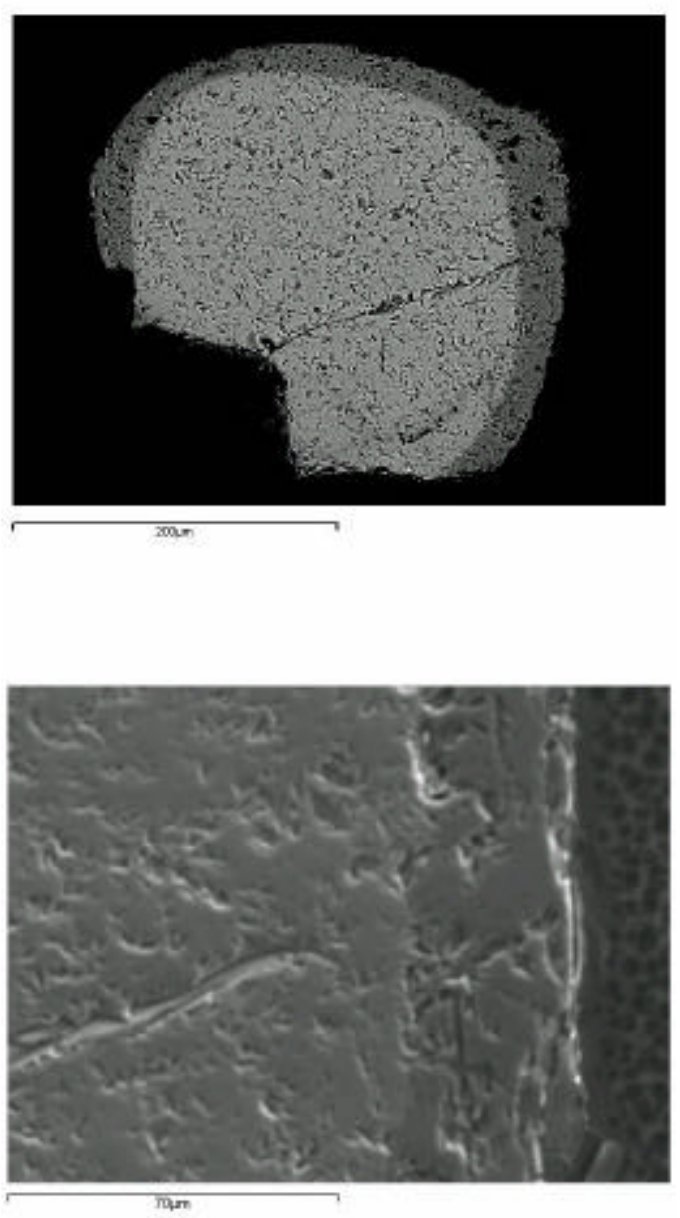

Figure 4: BSE (top) and SE (bottom) images of a chromite grain. In the BSE image only the "core" and "inner rim" are visible, whilst in the magnified SE image there is a third "outer rim" that is visible but the core and inner rim are indistinguishable. Geochemical compositions of these three zones are given in Table 1.
Contact: AH Menzies, PO Box 38668, Pinelands, 7430, South Africa, E-mail: Andrew.Menzies@minserv.co.za 